\title{
Working
}

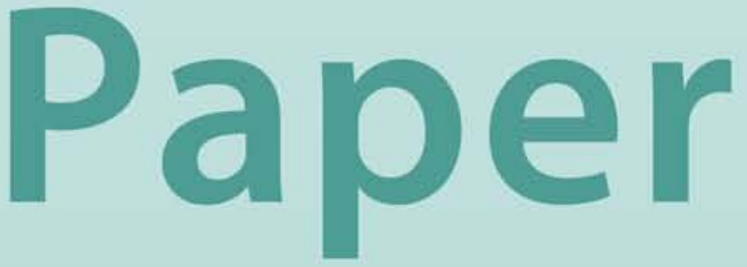




\section{The Dark Side of \\ Bank Wholesale Funding}

Rocco Huang and Lev Ratnovski 


\title{
IMF Working Paper
}

\author{
Research Department
}

\section{The Dark Side of Bank Wholesale Funding}

\section{Prepared by Rocco Huang and Lev Ratnovski ${ }^{1}$}

\author{
Authorized for distribution by Stijn Claessens
}

July 2010

\begin{abstract}
This Working Paper should not be reported as representing the views of the IMF. The views expressed in this Working Paper are those of the author(s) and do not necessarily represent those of the IMF or IMF policy. Working Papers describe research in progress by the author(s) and are published to elicit comments and to further debate.

Banks increasingly use short-term wholesale funds to supplement traditional retail deposits. Existing literature mainly points to the "bright side" of wholesale funding: sophisticated financiers can monitor banks, disciplining bad but refinancing good ones. This paper models a "dark side" of wholesale funding. In an environment with a costless but noisy public signal on bank project quality, short-term wholesale financiers have lower incentives to conduct costly monitoring, and instead may withdraw based on negative public signals, triggering inefficient liquidations. Comparative statics suggest that such distortions of incentives are smaller when public signals are less relevant and project liquidation costs are higher, e.g., when banks hold mostly relationship-based small business loans.
\end{abstract}

\section{JEL Classification Numbers:}

Keywords:

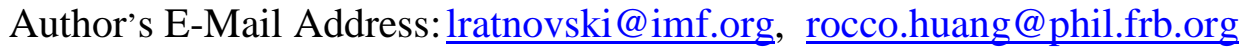

\footnotetext{
${ }^{1}$ Rocco Huang is from the Federal Reserve Bank of Philadelphia and Lev Ratnovski is from the International Monetary Fund. We thank Viral Acharya, Stijn Claessens, and Charles Kahn for very helpful comments. We also appreciate the feedback from the participants at the Cleveland Fed Conference on Identifying and Resolving Financial Crises, Basel Committee-CEPR-JFI Workshop on Risk Transfer Mechanisms and Financial Stability, RUG-DNB-JFS Conference on Perspectives on Financial Stability, CREDIT (Venice), IMF-World Bank conference on Risk Analysis and Risk Management, Bank of Canada workshop on Securitized Instruments, CesIfo-Bundesbank conference on Risk Transfer, Federal Reserve System Committee on Financial Structure and Regulation, European Banking Center conference on Financial Stability, and American Economic Association Annual Meeting (2010). The views expressed in this paper are those of the authors and do not necessarily represent those of the International Monetary Fund, the Federal Reserve Bank of Philadelphia, or the Federal Reserve System.
} 


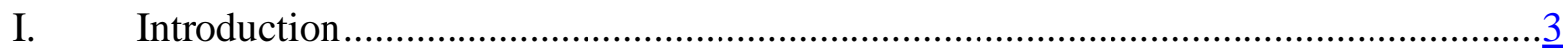

II. The Bright Side of Wholesale Funding …................................................................ 1

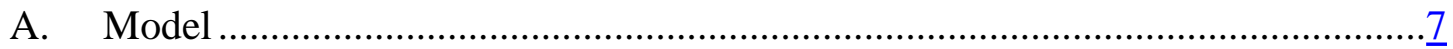

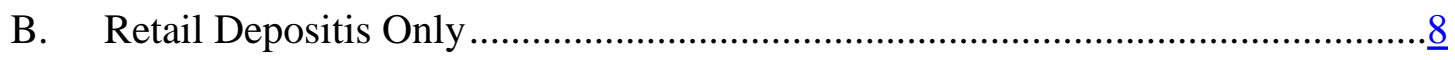

C. Wholesale Funds: Welfare Maximization ........................................................ $\underline{9}$

D. Wholesle Funds: Private Equilibrium ...........................................................

III. The Dark Side of Wholesale Funding ................................................................

A. Welfare Maximization ................................................................................. 11

B. Incentives of the Wholesale Financier .....................................................13

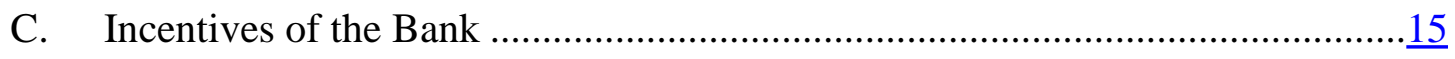

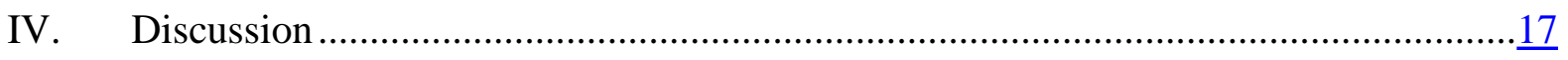

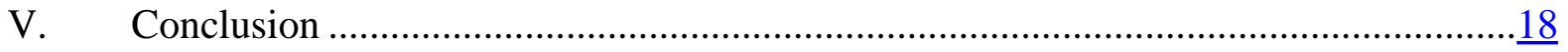

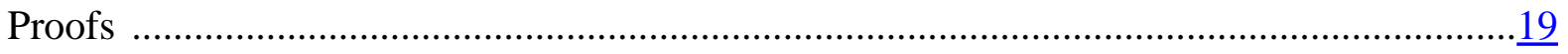

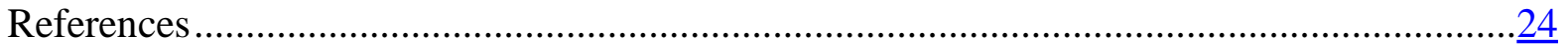

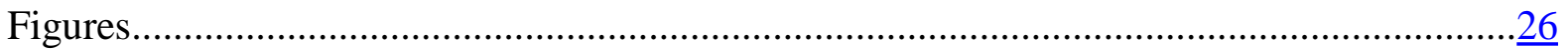




\section{Introduction}

Banks increasingly borrow short-term wholesale funds to supplement retail deposits (Feldman and Schmidt, 2001). Through wholesale money markets, they attract cash surpluses from nonfinancial corporations, households (via money market mutual funds), other financial institutions, etc. Wholesale funds are usually raised on a short-term rollover basis with instruments such as large-denomination certificates of deposits, brokered deposits, repurchase agreements, Fed funds, and commercial paper.

The existing literature mainly points to the "bright side" of wholesale funding: exploiting valuable investment opportunities without being constrained by the local deposit supply, the ability of wholesale financiers to provide market discipline (Calomiris, 1999) and to refinance unexpected retail withdrawals (Goodfriend and King, 1998). However, some of these benefits were not realized in the recent mortgage banking crisis (Acharya et al., 2008; Huang and Ratnovski, 2009). Indeed, the crisis demonstrated how banks can use wholesale funds to aggressively expand lending and compromise credit quality, particularly when financiers exercise insufficient market discipline. Later, at the refinancing stage, there is a risk that wholesale financiers abruptly withdraw upon a hint of negative news, triggering inefficient liquidations.

This paper attempts to reconcile the traditional view on the virtues of wholesale funding with its potentially negative effects. The key insight we suggest is that wholesale funding is beneficial when informed, but may lead to inefficient liquidations when uninformed. Formally, we consider a bank that finances a risky long-term project with two sources of funds: retail deposits and wholesale funds. Retail deposits are sluggish, insensitive to risks (partly because they are insured), and provide a stable source of long-term funding. ${ }^{2}$ Wholesale funds are relatively sophisticated, since their providers have the capacity to acquire information on the quality of bank projects. However, they are supplied on a rollover basis and have to be refinanced before final returns are realized, or the bank is forced into liquidation.

Our modelling approach builds on Calomiris and Kahn (1991, hereafter CK). We take CK as a benchmark of the "bright side" of wholesale funding. CK show that "sophisticated" wholesale financiers add value through their capacity to monitor banks and impose market discipline (force liquidations) on loss-making ones. Moreover, they show that monitoring incentives of wholesale financiers are maximized when they are senior at refinancing stage, because it allows them to internalize the benefits of monitoring (payoffs in early liquidations).

\footnotetext{
${ }^{2}$ The "sluggishness" of retail deposits is a well-established stylized fact (Feldman and Schmidt, 2001; Song and Thakor, 2007). Retail deposits are typically insured by the government. Their withdrawals are motivated mostly by individual depositors' liquidity needs and thus are predictable based on the law of large numbers. Another reason for the "sluggishness" is the high switching costs associated with transaction services that retail depositors receive from banks (Kim et al., 2003; Sharpe, 1990, 1997). As a result, although some accounts are formally demandable, retail deposits provide a relatively stable source of long-term funds for banks. However, the local retail deposit base is quasi-fixed in size, since it is usually prohibitively expensive to expand it in the medium term (Billett and Garfinkel, 2004; Flannery, 1982).
} 
In practice, short-term wholesale funds indeed enjoy de facto (effective) seniority because of the sequential service constraint and the relative sluggishness of insured retail depositors. This was the main reason why in almost all recent bank failures (e.g., Continental Illinois, Northern Rock, IndyMac) short-term wholesale financiers were able to exit ahead of retail depositors without incurring significant losses. Interestingly, the well-publicized retail run on Northern Rock took place only after the bank had nearly exhausted its liquid assets to pay off the exit of short-term wholesale funds (Shin, 2008; Yorulmazer, 2008). ${ }^{3}$

We then introduce into the benchmark CK model a single novel feature: a costless but noisy public signal on bank project quality. This represents public information that wholesale financiers can costlessly process and that is a noisy proxy for bank-specific fundamentals. Examples include market prices or credit ratings for traded assets (e.g., mortgage-backed securities), performance of other similar banks, or various market- or sector-wide indicators (e.g., house or energy prices). Wholesale financiers may use the public signal when costly private monitoring did not produce precise information on bank fundamentals (because of either low investment in monitoring or merely bad luck).

We show that this minor and plausible change to the CK setup can, under some conditions, lead to outcomes consistent with the "dark side" of wholesale funding seen in recent events. In our model, the presence of a costless but noisy signal:

- Lowers the incentives of wholesale financiers to monitor;

- Gives wholesale financiers excess incentives to liquidate banks based on noisy public information; and

- Importantly, these distortions become stronger when wholesale financiers are more senior claimants to the liquidated assets (in contrast to $\mathrm{CK}$ ).

The mechanism of these effects is that, absent a noisy public signal, uninformed wholesale financiers always roll over funding at the refinancing stage as banks are on average solvent (no news is good news). However, with a noisy public signal, wholesale financiers uninformed about bank-specific fundamentals can now choose to liquidate a bank based solely on a negative but possibly very imprecise public signal.

The key inefficiency is that the incentives of wholesale financiers to liquidate based on noisy information can be too high compared to the socially optimal ones, particularly when they are senior claimants on the liquidation value. The reason is that senior

\footnotetext{
${ }^{3}$ Marino and Bennett (1999) analyze six major bank failures in the US between 1984 and 1992 and find that uninsured large deposits fell significantly relative to small insured deposits prior to failures. During the New England banking crisis, failing banks experienced a 70 percent decline in uninsured deposits in their final two years of operation while being able to raise insured deposits to replace the outflow. Billett, Garfinkel, and O'Neal (1998) also find that banks typically raised their use of insured deposits vis-a-vis wholesale deposits after being downgraded by Moody's.
} 
wholesale financiers can obtain a larger share of the liquidation value of assets, at the expense of providers of long-term funds such as passive core depositors. As a second-round effect, when wholesale financiers anticipate a high likelihood of an early liquidation with a safe exit, they become less interested in acquiring costly private information on bank project quality in the first place.

Therefore, in the presence of a noisy public signal, higher effective seniority of short-term wholesale funds has two effects. One, in line with CK, is the positive first-order effect that rewards monitoring and market discipline efforts. Another, a novel one, is the negative effect that increases the payoff to liquidating banks based on overly noisy information. The socially optimal seniority of short-term wholesale funds must therefore trade-off the two offsetting effects. We find that such welfare-maximizing seniority has an interior optimum. While the monitoring incentives of wholesale financiers increase in seniority for low values of seniority (the CK effect), they decrease for higher values of seniority when higher seniority translates purely into more liquidations. Deviations from that interior optimum to either side result in less monitoring and possibly more inefficient liquidations. This result contrasts with the CK benchmark in which higher seniority for the sophisticated funds is always better.

The precision of the noisy public signal (i.e., the probability that it is correct) is one of the key parameters of the model. Its one interpretation is the availability of relevant public signals on individual bank performance. This may vary across banks depending, for example, on asset type. For example, while the market prices of mortgage-backed securities (MBS) or house price changes can shed light on the fundamentals of a typical mortgage bank, few similarly relevant public signals exist for traditional banks that hold mainly relationship-based small business loans. The signal precision can also be interpreted as the correlation between an individual bank's fundamentals with system-wide outcomes or indicators. With the proliferation of "risk transfer" and "risk dispersion" mechanisms, individual bank performances have become increasingly correlated, so that public signals now provide more relevant information on an individual bank's performance. Note, however, that these costless public signals can only provide imperfect information on an individual bank's true asset quality.

Our results reveal that the incentives for short-term wholesale financiers to liquidate strategically based on a noisy negative signal are higher, and therefore the welfare-maximizing seniority of wholesale funds (which compensates for excess liquidation incentives) is lower, when:

- The noisy public signal is more precise, yet not as precise as to make liquidation decisions based on it socially optimal;

- The share of passive deposits in bank liabilities is higher. The seemingly safe buffer of passive retail deposits in fact makes early liquidations less costly for wholesale financiers and discourages them from information acquisition efforts; 
- Liquidation value of bank assets is higher. Liquidation value reflects bank's cash reserves and the marketability of its long-term assets. By conventional wisdom, a larger liquidity buffer should better protect a bank against withdrawals. However, our setup highlights offsetting incentive effects: a larger buffer increases the financiers' incentives for inefficient "noisy" liquidations by lowering their cost.

- Interest rate offered to wholesale financiers in case of success is lower. A competitive interest rate reflects the return on alternative use of money; it is lower for example in times of abundant liquidity supply. With a low interest rate, wholesale financiers have less to gain if a project succeeds in the long term. This encourages early liquidation.

In a bank cross-section, these predictions suggest that the use of senior short-term funds is beneficial in "traditional" banks that hold mainly opaque and nontradable relationship loans, consistent with the "bright side" predictions of CK. Yet the "dark side" negative effects are likely to play a significant role in banks with large exposures to standardized and tradable arm's length assets with readily available public information, particularly when short-term wholesale financiers are senior claimants. ${ }^{4}$ At the same time, we show that private incentives would in fact drive arm's length banks towards actively using senior short-term wholesale funds, since interest rates demanded on them are lowest when assets are marketable and public signals are informative. Therefore, CK's insights best apply to the traditional relationship banking business with limited public information on asset quality, while our model sheds light on the new banking business characterized by arm's length transactions, high interbank correlations, and the availability of relevant public signals such as market prices and credit ratings.

To sum up, we show that the use and high seniority of wholesale funds is not always socially beneficial. In the presence of a costless but noisy signal on bank quality, higher seniority can reduce monitoring and encourage inefficient liquidations. Social welfare is constrained-maximized for an intermediate level of seniority, which depends on the bank's funding structure (i.e., share of passive retail deposits on the liability side), the precision of public signals on bank project quality (which often depends on the type of assets held), liquidation value of bank assets, and interest rates offered to wholesale financiers. This is a novel result that usefully contrasts with $\mathrm{CK}$ and bears close resemblance to recent developments in the credit market, as well as some earlier instances of bank failures. It reveals the "dark" side of short-term wholesale funding.

The rest of the paper is structured as follows. Section 2 sets up the benchmark CK-type model of the "bright side" of wholesale bank funding. Section 3 introduces the costless but noisy signal on bank project quality and analyzes the "dark side" of wholesale funding. Section 4 discusses some features of our model and briefly outlines policy insights. Section 5 concludes.

\footnotetext{
${ }^{4}$ Note that banks holding securitized assets (e.g. MBS) appear particularly vulnerable to the risk of premature liquidations: trading of assets provides a public signal on quality, and also raises their liquidated value.
} 


\section{The Bright Side of Wholesale Funding}

\section{A. Model}

We start by outlining a version of the Calomiris and Kahn (1991) model, which we use to describe a benchmark "bright side" of bank wholesale funding. Consider an economy consisting of a bank (with access to an investment project) and two types of financiers: retail and wholesale. There are three dates $(0,1,2)$, no discounting, and everyone is risk-neutral.

The project A bank has exclusive access to a profitable but risky long-term project. For each unit invested at date 0 , at date 2 the project returns $X$ with probability $p$ or 0 with probability $1-p$, with a positive net present value: $X p>1$. The project may also be liquidated at date 1 returning $L<1$ per unit initially invested. The maximum investment size is 1 .

Funding The bank has no initial capital and needs to borrow in order to invest. There are two types of financiers:

1. The "retail depositors" are unsophisticated, passive, and scarce. They never get advance information on date 2 project realization, and never withdraw before date 2 , providing the bank with a source of stable long-term (yet formally demandable) funds. The interest rate payable on retail deposits (date 0 to date 2 ) is risk-insensitive and fixed at $R_{D}: 1 \leq R_{D}<p X$. The bank is endowed with a fixed deposit base of $D<1$ and it is prohibitively costly to expand it within the horizon of the model.

2. The "wholesale financier" is sophisticated, has an unlimited supply of funds, but is short-term. He can choose to monitor the bank before date 1 and use obtained information to decide whether to refinance or liquidate the bank at date 1 .

The wholesale financier can lend to the bank any amount at date 0 against real expected return $\rho$, which reflects his opportunity cost of funds. The bank's project is better than alternative investment opportunities so initial funding is always available: $1 \leq \rho<p X$. The amount of wholesale funds attracted by the bank is denoted $W$. Since the maximum investment size is $1, W \leq 1-D$.

Wholesale funding needs to be refinanced at date 1 . If the wholesale financier refuses to roll over, the bank is forced into liquidation. The endogenous interest rate on wholesale funds is denoted $R$. We assume that $R$ is set from date 0 to date 2 . This allows us to avoid hold-up by the wholesale financier at date 1 (cf. von Thadden, 1995).

We model wholesale funding as provided by one single agent, abstracting from competition and coordination problems among multiple wholesale financiers (see 
Diamond and Dybvig, 1983; Rochet and Vives, 2004; and Von Thadden, 2004, for examples of analysis of such problems).

Monitoring The wholesale financier can obtain advance information on the project's date 2 realization by monitoring the bank between dates 0 and 1 . He chooses the intensity of monitoring $m(0 \leq m<1)$, and incurs corresponding cost $C(m)(C(0)=0$, $\left.C(1)=\infty, C^{\prime}(0)=0, C^{\prime}(m)>0, C^{\prime \prime}(m)>0\right)$. The wholesale financier then receives precise information of date 2 realization with probability $m$. He receives no information at all with probability $1-m$, in which case he knows that monitoring has failed.

Liquidation and creditor seniority If the wholesale financier refuses to roll over initial funding at date 1 , the bank is liquidated. Since $L<1$, all creditors cannot be repaid in full. The division of liquidation value $L(D+W)$ among them is governed by seniority rules. The relative seniority of the wholesale financier versus retail depositors is described by the share $s(0 \leq s \leq 1)$ of the liquidation value he receives.

To keep the model tractable, we assume that the amount of wholesale funding attracted by the bank is not insignificant compared to the liquidation value:

$$
p W>L
$$

This ensures that $p W R>s L(D+W)$, so that the wholesale financier never liquidates a bank based solely on a prior $p$ to receive $s L(D+W)$ instead of waiting for $p W R$ expected at date 2 . This reflects a stylized fact that "no news is good news" and bank runs are uncommon absent negative information.

For determinacy, we assume that all agents prefer bank continuation to liquidation when they are otherwise indifferent between the two options. This implies, in particular, that the bank always prefers continuation, since it receives nothing in liquidation, and that date 1 liquidation can be triggered only by the wholesale financier.

The benchmark analysis proceeds in three steps. We start with the basic case of retail deposit funding. We then show the positive effects of wholesale funds: expanding investment beyond the constraints of the fixed deposit base, and monitoring that gives rise to market discipline. Finally, we verify that the equilibrium private choices of the bank and the wholesale financier are the socially optimal ones.

\section{B. Retail deposits only}

Consider a bank funded by retail deposits only. The initial investment $D$ is lower than the maximum possible investment size of 1 ; such spare capacity is inefficient, because the 
bank's project has a positive net present value. Furthermore, the bank always continues until date 2: the bank prefers continuation, while retail depositors are uninformed and passive. This means that bad projects are not terminated at date 1 (to preserve liquidation value $L$ ) but continue until date 2 , returning 0 . This is the second source of inefficiency. The monetary value of social welfare when the bank is financed with retail deposits only is:

$$
\Pi_{D e p}=D(p X-1)
$$

\section{Wholesale funds: Welfare maximization}

Now consider a bank that also uses $W$ of wholesale funds. In this section, we derive the socially optimal monitoring and continuation decisions of the wholesale financier and the amount of wholesale funds attracted by a bank.

Consider first the continuation decision. If monitoring produces precise information on date 2 project return, a good bank should be refinanced at date $1(X>L)$ while a bad one should be liquidated $(L>0)$. When monitoring yields no information, so that project quality is unknown, a bank should be refinanced, since $X p>L$.

The optimal intensity of monitoring, $m^{*}$, and the optimal use of wholesale funds, $W^{*}$, are obtained by maximizing the monetary value of social welfare:

$$
\Pi=(D+W)(p X+m(1-p) L-1)-C(m) .
$$

This yields the maximum possible amount of wholesale funds, so that the complete initial investment 1 is undertaken:

$$
W^{*}=1-D
$$

and $m^{*}$ given by:

$$
C^{\prime}\left(m^{*}\right)=(1-p) L
$$

Comparing (2) and (3) highlights the beneficial effects of the use of wholesale funds: higher investment volume $D+W=1$ instead of $D$, and the preservation of some bad banks' liquidation value $m^{*}(1-p) L$ at the cost of monitoring $C\left(m^{*}\right)$.

\section{Wholesale funds: Private equilibrium}

We now study the private choices of the wholesale financier and the bank, and compare the choices with the social optimum. 
Wholesale financier Between dates 0 and 1, the wholesale financier chooses the intensity of monitoring, and then observes the outcome of his monitoring. Then, at date 1 , he chooses whether to refinance or liquidate the bank. The financier's continuation decision is in line with the social optimum: when monitoring yields precise information on project quality, he has incentives to refinance a good bank $(W R>s L(D+W))$ and liquidate a bad one $(s L(D+W)>0)$. When monitoring yields no information, the wholesale financier rolls over funding, since, by (1), $p W R>s L(D+W)$.

In choosing the intensity of monitoring $m$, the financier maximizes:

$$
\Pi^{W}=p W R+m(1-p) s L(D+W)-C(m),
$$

which obtains the private choice of $m^{W}$, given by:

$$
C^{\prime}\left(m^{W}\right)=(1-p) s L(D+W)
$$

Observe from (4) and (5) that $m^{W}=m^{*}$ for $s=1$ and $D+W=1$. This means that the wholesale financier chooses the optimal intensity of monitoring when he is a senior creditor at date 1 and the amount of wholesale funding is the maximum possible. The intuition is that high seniority and high volume allow the wholesale financier to fully internalize the benefits of monitoring: his payoff in monitoring-enabled liquidations $s L(D+W)$ is increasing in seniority and the volume of wholesale funds.

Bank The bank makes decisions on the amount of wholesale funds $W$ and the funds' creditor seniority $s$. The bank's surplus is:

$$
\Pi^{B}=p\left[D\left(X-R_{D}\right)+W(X-R)\right]
$$

The interest rate $R$ demanded by the wholesale financier, obtained from the zero-profit condition, is:

$$
R=\frac{W \rho+C\left(m^{W}\right)-m^{W}(1-p) s L(D+W)}{W p} .
$$

Lemma $1 \Pi^{B}$ increases in $s$ and $W$ and hence is maximized for $W=1-D=W^{*}$ and $s=1=s^{*}$.

\section{Proof. See Appendix.}

The intuition is that $\Pi^{B}$ increases in $s$ because $R$ decreases in $s$ : when the wholesale financier receives more in early liquidations, he requires lower compensation for his funds. $\Pi^{B}$ increases in $W$ because with a higher amount of wholesale funds, the bank is able to 
invest more and the per-unit cost of monitoring declines. We can summarize the benchmark result in Proposition 1:

Proposition 1 In the benchmark "bright side" case, the bank's decisions on the amount and the creditor seniority of wholesale funds, as well as the wholesale financier's decisions on monitoring and continuation, are all socially optimal. The outcome is $W=W^{*}, s=s^{*}, m=m^{*}$, and only a bank known by the wholesale financier to be a bad one is liquidated.

\section{The Dark Side of Wholesale Funding}

We now turn to the analysis of the "dark side" of bank wholesale funding. In this section we show how a plausible change to the "bright side" CK-style setup of Section 2 can significantly alter its results.

We introduce an additional source of information: a free but noisy public signal on date 2 project realization, which the wholesale financier receives prior to date 1 but after he has made a decision on the intensity of monitoring. The wholesale financier can use this signal when his own monitoring yields no information (either because of the low intensity of monitoring or merely by bad luck). Although the signal is free, it is complex, and therefore not received by retail depositors.

We specify the signal to have the same distribution of outcomes as that of the underlying project. It takes two values: "positive" or "negative" and is characterized by a precision parameter $\theta(0 \leq \theta \leq 1 ; \theta=0$ for complete noise and $\theta=1$ for precise information). The probability of receiving a positive signal is $p$ (the same as that for $X$ at date 2). Conditional on this, the probability of getting $X$ at date 2 is $[p+\theta(1-p)]$, and that of getting 0 is $[(1-p)-\theta(1-p)]$. The probability of a negative signal is $1-p$. Conditional on this, the probability of getting $X$ at date 2 is $[p-\theta p]$, and that of getting 0 is $[(1-p)+\theta p]$.

We show that such a relatively minor twist can generate outcomes contrasting to those of the CK-style setup. Previously, the wholesale financier always refinanced the bank at date 1 if his private monitoring yielded no information. That was consistent with both his private incentives and welfare maximization. Now, with the introduction of the signal described above, the wholesale financier has lower incentives to monitor and excess incentives to liquidate the bank based on noisy public information.

\section{A. Welfare maximization}

We start by outlining the benchmark socially optimal decisions on monitoring, refinancing, and the use of wholesale funds in the presence of a free but noisy signal on bank project quality. 
Refinancing at date 1 When the wholesale financier's monitoring before date 1 produces precise information on project quality, the noisy public signal cannot add information. As before, a good bank will be refinanced and a bad one, liquidated.

Without the noisy signal, continuation at date 1 is always optimal when private monitoring produces no information on project quality. The noisy signal refines date 1 expectations of date 2 project outcome. When a noisy signal is positive, the posterior of date 2 project success increases to $p+\theta(1-p)$, so it naturally remains optimal that the bank is refinanced at date 1 . However, when a noisy signal is negative, the posterior of project success falls to $[p-\theta p]$, and the optimal continuation decision starts to depend on the signal's precision, $\theta$. If the precision is low so that $[p-\theta p] p X \geq L$, it remains optimal to refinance the bank. However, if precision is high enough so that $[p-\theta p] p X<L$, it becomes socially optimal to liquidate the bank based solely on a noisy signal. The threshold value of $\theta$ is:

$$
\theta^{*}=1-\frac{L}{p^{2} X}
$$

Monitoring Now consider how the noisy signal affects the optimal intensity of monitoring and the amount of wholesale funding. Recall that, when the precision of the signal is low, $\theta \leq \theta^{*}$, it is optimal to disregard it. The maximization problem is the same as in the benchmark case (3); the optimal amount of wholesale funding is $W^{*}=1-D$ and the optimal monitoring intensity is $m^{*}$ given in (4).

When the precision of the noisy signal is high, $\theta>\theta^{*}$, it is optimal to use it and liquidate the bank when the signal is negative. The monetary value of social welfare is:

$$
\Pi_{L i q}=(D+W)(m[p X+(1-p) L]+(1-m)[p[p+\theta(1-p)] X+(1-p) L]-1)-C(m) .
$$

The term $m[p X+(1-p) L]$ reflects the payoff from private monitoring that produces precise information on project quality. The term $(1-m)[p[p+\theta(1-p)] X+(1-p) L]$ is novel. It represents the payoff from using the noisy signal when private monitoring produces no information and liquidating the bank upon a negative signal: $p$ is the probability of a positive signal conditional on which the bank is refinanced and yields $X$ with probability $[p+\theta(1-p)] ;(1-p)$ is the probability of a negative signal conditional on which the bank is liquidated to preserve $L$.

As before, the social welfare (9) is increasing in $W$, so that it is optimal to use as much wholesale funding as possible: $W_{L i q}^{*}=1-D=W^{*}$. The optimal intensity of monitoring $m_{\text {Liq }}^{*}$ is given by:

$$
C^{\prime}\left(m_{\text {Liq }}^{*}\right)=p(1-p)(1-\theta) X
$$

Observe that $m_{L i q}^{*}<m^{*}$. This is easy to verify by applying the condition for using the noisy signal $[p-\theta p] p X<L$ to (4) and (10). The intuition is that the availability of a free but noisy signal makes the private information obtained through costly monitoring less valuable. 


\section{B. Incentives of the wholesale financier}

Now consider the private choices of the wholesale financier on (1) whether to liquidate or refinance the bank at date 1 and (2) how intensively to monitor the bank prior to date 1 .

Inefficient liquidations As before, when monitoring yields precise information on the quality of the bank project, the wholesale financier has incentives to follow its outcome: refinance a bank known to be good and force liquidation of a bad one. When monitoring fails to yield information, the uninformed wholesale financier can now use the noisy public signal. Conditional on a negative signal, his expected continuation payoff is $[p-\theta p] W R$ and his liquidation payoff is $s L(D+W)$. For the wholesale financier, it is privately optimal to follow a noisy signal and liquidate the bank for:

$$
s L(D+W)>[1-\theta] p W R .
$$

Expression (11) can be interpreted either as sufficiently high precision of the noisy signal:

$$
\theta>\theta^{W}=1-\frac{s L(D+W)}{p W R},
$$

or as sufficiently high creditor seniority of the wholesale financier:

$$
s>s^{W}=\frac{(1-\theta) p W R}{L(D+W)} .
$$

Note that the incentives of the wholesale financier to liquidate the bank increase in $s$. He has no incentives for early liquidations when junior $\left(\theta_{s=0}^{W}=1\right)$, but may have excessive incentives to liquidate when senior $\left(\theta_{s=1}^{W}<\theta^{*}\right)$.

Monitoring Consider the monitoring choice of the wholesale financier. When he is sufficiently junior, $s \leq s^{W}$, he disregards the noisy signal, so his private choice of monitoring intensity is the same as the benchmark $m^{W}$ given in (5).

However, when he is sufficiently senior, $s>s^{W}$, he has incentives to use the noisy signal and liquidate the bank when the signal is negative. Then, in choosing monitoring intensity, he maximizes:

$\Pi^{W}=m[p W R+(1-p) s L(D+W)]+(1-m)[p[p+\theta(1-p)] W R+(1-p) s L(D+W)]-C(m)$

which obtains:

$$
C^{\prime}\left(m_{\text {Liq }}^{W}\right)=p(1-p)(1-\theta) W R_{L i q}
$$

Observe that, unlike for $m^{W}$ given in (5), $s$ does not enter directly into the specification of 
$m_{L i q}^{W}$ given in (15). Rather, it affects $m_{L i q}^{W}$ indirectly through $R_{L i q}$. To see that, consider the interest rate charged by the wholesale financier:

$$
R_{L i q}=\frac{W \rho+C\left(m_{L i q}^{W}\right)-(1-p) s L(D+W)}{m_{L i q}^{W} W p+\left(1-m_{L i q}^{W}\right)[p+\theta(1-p)] W p} .
$$

As $s$ increases and the wholesale financier receives more in date 1 liquidations, he requires a lower compensation at date 2 ; hence $R_{L i q}$ decreases in $s$. And since $m_{L i q}^{W}$ increases in $R_{L i q}$, it decreases in $s$. The contrasting effects of creditor seniority on the behavior of the wholesale financier with and without a noisy public signal are illustrated in Figure 1. Therefore, $s=s^{W}$ is a threshold point not only for the wholesale financier's liquidation decision but also for his choice of monitoring intensity.

Lemma 2 Consider $s^{W}$, the threshold point for the wholesale financier's use of the noisy public signal.

1. $s^{W}$ decreases in $\theta$ and $L$; it decreases in $D$ and increases in $W$ (provided that $D+W=1)$.

2. For $s \leq s^{W}$, the wholesale financier never liquidates a bank based on a noisy public signal and the intensity of his monitoring increases in his creditor seniority: $\partial m^{W} / \partial s>0$.

3. For $s>s^{W}$, the uninformed wholesale financier chooses to liquidate a bank following a negative noisy signal and the intensity of his monitoring decreases in seniority: $\partial m_{\text {Liq }}^{W} / \partial s<0$.

4. Monitoring and interest rate functions are continuous at $s^{W}: m_{s=s^{W}}^{W}=m_{L i q, s=s^{W}}^{W}$ and $R_{s=s^{W}}=R_{L i q, s=s^{W}}$.

Proof. See Appendix.

Socially optimal seniority of wholesale funds Based on the incentives of the wholesale financier identified in Lemma 2, we can now formulate in Proposition 2 the socially optimal seniority and use of wholesale funds.

Proposition 2 Consider the case with possible welfare-reducing liquidations: $\theta_{s=1}^{W}<\theta \leq \theta^{*}$. The socially optimal creditor seniority of the wholesale financier is $s=s^{W}, s^{W}<1$. Setting $s=s^{W}$ aligns the continuation decision of the wholesale financier with the social optimum, and there are no inefficient liquidations. It also maximizes the intensity of monitoring, albeit at a level below the social optimum: $m^{W}\left(s^{W}\right)<m^{*}$. All else equal, the incentives of the wholesale financier for inefficient liquidations are higher, and hence the socially optimal seniority of wholesale funding is lower, when the precision of the public signal $\theta$ is higher, the bank's liquidation value $L$ is higher, and there are more deposits D serving as buffer for wholesale funds' exit. 
Point $s^{W}$ can be thought of as the highest seniority consistent with the "bright side" of wholesale funding. For $s>s^{W}$, the wholesale financier becomes sufficiently senior to undertake inefficient liquidations of banks based on overly noisy public information, and higher seniority leads to lower monitoring.

\section{Incentives of the bank}

The previous section has established the socially optimal seniority of the wholesale financier: an intermediate $s^{W}$. However, in practice the decision on creditor seniority is taken by a bank with the objective of maximizing its private surplus. We now study the bank's choice of creditor seniority and show that it can deviate from the social optimum.

The bank's choice of creditor seniority for the wholesale financier The bank has no incentives to assign creditor seniority below the socially optimal level, because for $s<s^{W}$ its surplus $\Pi^{B}$ given in (6) increases in $s$.

Consider, however, the private incentives for the bank to assign too high creditor seniority, $s>s^{W}$. The bank's cost is similar to the social one: losses when good projects are abandoned in inefficient liquidations. However, the bank also has a private benefit: offering the wholesale financier higher seniority reduces the interest rate $R$. Since the interest rate on deposits $R_{D}$ is fixed, this leads to an increase in the bank's surplus. If the net effect is positive (lower interest expense compensates the higher risk of inefficient liquidations), the bank has private incentives to offer too high seniority.

Indeed, recall that the bank's surplus at $s^{W}$ is:

$$
\Pi_{s=s^{W}}^{B}=p\left[D\left(X-R_{D}\right)+W\left(X-R_{s=s^{W}}\right)\right]
$$

with $R$ given by (7).

The bank's surplus for $s>s^{W}$ is:

$$
\Pi_{\text {Liq }}^{B}=\left[p-\left(1-m_{L i q}^{W}\right) p(1-\theta)(1-p)\right]\left[D\left(X-R_{D}\right)+W\left(X-R_{L i q}\right)\right]
$$

with $R_{L i q}$ given by (16). (Note immediately that $\Pi_{L i q}^{B}$ increases in $W$, so that the bank chooses socially optimal $W=1-D$.) It is instructive to compare the two expressions above. Observe that in $\Pi_{L i q}^{B}$ the first multiplicative term features a lower probability of bank project success than that in $\Pi_{s=s_{W}}^{B}$; the difference is the probability $\left(1-m_{L i q}^{W}\right) p(1-\theta)(1-p)$ of inefficient liquidations. The second term - the bank's surplus conditional on project success, at the same time, is higher in $\Pi_{L i q}^{B}$ than in $\Pi_{s=s^{W}}^{B}$, since $R_{L i q}<R_{s=s^{W}}$ due to higher $s$. Indeed, consider the bank's surplus as a function of 
$s$. Early liquidations trigger a discrete drop in $\Pi^{B}$ at $s^{W}$. The value of that decline is:

$$
\Pi_{s=s^{W}}^{B}-\Pi_{L i q, s=s^{W}}^{B}=\left(1-m_{L i q}^{W}\right) p(1-\theta)(1-p)\left[D\left(X-R_{D}\right)+W(X-R)\right] .
$$

However, after the initial drop, $\Pi_{s>s^{W}}^{B}$ may start increasing in $s$.

Consider the derivative of $\Pi_{L i q}^{B}$ w.r.t. $s$ :

$$
\frac{d \Pi_{L i q}^{B}}{d s}=\frac{d m_{L i q}^{W}}{d s} p(1-\theta)(1-p)\left[D\left(X-R_{D}\right)+W\left(X-R_{L i q}\right)\right]-\frac{d R_{L i q}}{d s}\left[p-\left(1-m_{L i q}^{W}\right) p(1-\theta)(1-p)\right]
$$

The first term on the right-hand side represents the impact of higher seniority on monitoring and is negative, $d m_{L i q} / d s<0$, since with higher $s$ the wholesale financier monitors the bank less, resulting in more inefficient liquidations. However, the second term is positive, $-d R_{L i q} / d s>0$, since with higher $s$ the bank pays a lower interest rate on wholesale funding (the wholesale financier is compensated more in early liquidations instead). Therefore, the overall effect of higher $s$ on $\Pi_{L i q}^{B}$ is ambiguous.

The full analytical examination of $\Pi_{L i q}^{B}$ is complicated by the fact that its convexity depends on the shape of $C(m)$, including the third derivative. Since the shape of $C(m)$ is not at the core of our argument, we make a simplifying restriction to focus the exposition on the effects that we want to highlight. Specifically, we consider a very well-behaved $C(m)$, such that $m$ is effectively constant, $m=m_{C}$, in the relevant range of parameter values. This corresponds to $C(m)$ having a sharp J-shape that is almost horizontal until $m_{C}$ and almost vertical after that. Figure 2 depicts possible shapes of $\Pi_{L i q}^{B}$ that are allowed or ruled out by this simplification, to help us understand the dimensions of generality we are preserving or losing.

The key impact of the restriction is that the first term in (20) becomes zero, while the second term becomes a constant. We therefore are left with a linear and increasing $\Pi_{L i q}^{B}$, so that the global maximum of $\Pi^{B}$ is achieved in either $s=s^{W}$ when $\Delta \Pi^{B}=\Pi_{L i q, s=1}^{B}-\Pi_{s=s^{W}}^{B}$ is positive, or $s=1$ otherwise. From (17) and (18),

$\Delta \Pi^{B}=$ $p\left[R_{s=s} W-R_{L i q, s=1}\right] W-\left(1-m_{C}\right) p(1-\theta)(1-p)\left[D\left(X-R_{D}\right)+W\left(X-R_{L i q, s=1}\right)\right]$.

The first term above reflects a lower interest expense for more senior wholesale funds, while the second term reflects the probability of inefficient liquidations.

We examine cross-sectional properties of $\Delta \Pi^{B}$ with respect to four key parameters of the model: $\theta, L, D$, and $W$, and summarize the findings in Lemma 3 :

Lemma $3 \Delta \Pi^{B}$ increases in $\theta$ and $L$; it increases in $D$ and decreases in $W$.

Proof. See Appendix. 
The intuition is that, higher $\theta, L$, and $D$ reduce the cost of early liquidations for the wholesale financier, which translates into a lower interest rate charged by him and accordingly higher surplus for the bank. Higher $W$ has the opposite effect since $W=1-D$

We then conduct a simple numerical exercise, to demonstrate how, within a plausible range of parameter values, $\Delta \Pi^{B}$ can be either positive or negative. The exercise validates the existence of both "bright" and "dark" sides of wholesale funding. The outcome of the exercise is illustrated in Figure 3. ${ }^{5}$

Based on Lemma 3 and the numerical analysis, we can now summarize in Proposition 3 the bank's incentives of assigning too high seniority to wholesale funds despite the risk of inefficient liquidations:

Proposition 3 The "dark side" of wholesale funding exists: the set of parameter values for which the bank assigns the wholesale financier too high seniority, subjecting itself to the risk of inefficient liquidations, is non-empty. All else equal, the bank has higher incentives to assign too high seniority to the wholesale financier when the precision of the public signal $\theta$ is higher, the bank's liquidation value $L$ is higher, and there are more deposits D serving as buffer for wholesale funds' exit.

\section{Discussion}

This section discusses some features of our model and briefly outlines policy insights.

Comparative statics Propositions 2 and 3 offer cross-sectional predictions on the risk of inefficient liquidations in different types of banks. They identify that banks are more likely to assign too high seniority to wholesale funds, and wholesale financiers are more likely to undertake inefficient liquidations, when the precision of the public signal on bank project quality $\theta$ and the bank's liquidation value $L$ are higher. These two predictions suggest a distinction between "traditional" banks that hold primarily relationship-based small business loans (associated with low $\theta$ and $L$ ) and "modern" banks that hold more tradable and arm's length assets such as mortgage loans or securities (associated with higher $\theta$ and $L$ ). The "bright side" of wholesale funding - beneficial monitoring and market discipline is likely to dominate in traditional banks, consistent with the original CK predictions. Yet the modern banks are likely to be negatively affected by the "dark side" of wholesale funding described by our model.

\footnotetext{
${ }^{5}$ The simulation is based on the following parameter values: $m=0.5, \rho=1, p=0.90, X=1.15$, $R_{D}=1.10$. $W$ takes the values of $0.25,0.5$, and 0.75 , respectively, in three different scenarios. We have considered alternative specifications, and confirmed that the properties revealed by the figures are robust to choosing other parameter values.
} 
Long-term funds and non-depository banks The model identifies long-term bank funding with "retail deposits" that are passive (never withdrawn at an intermediate date) and risk-insensitive (possibly due to deposit insurance). It is important to point out, however, that "retail deposits" in our model can be taken as a metaphor for all long-term funds (such as bonds or customer funds) that would likely lose out to short-term wholesale funds when scrambling for the liquidated assets. Consequently, our model can be taken to describe a broader conflict of interest between short-term and long-term bank financiers in non-bank financial institutions that may have no insured retail deposits whatsoever.

For example, the run on Bear Stearns (BSC) could be linked to the conflict of interest between short-term collateralized funds (such as repo's) and long-term funds (including funds due to customers and long-term borrowings), which accounted for about 42 percent of BSC's total liabilities. The short-term financiers withdrew, rapidly reducing BSC's pool of high-quality, highly liquid assets from $\$ 18.1$ billion on March 10, 2008 to $\$ 2$ billion three days later.

Policy implications In our model, the bank's suboptimal use of senior wholesale funds is driven by the private savings it receives from lower interest expenses. As the bank does not take into account the negative externality of its funding strategy on depositors, a Pigouvian tax on senior wholesale funds, similar to that proposed in Perotti and Suarez (2009), may help align the bank's incentives with the social optimum. In practice, this would likely correspond to taxing the use of short-term wholesale funds such as collateralized repo's, because short maturity and over-collateralization are good proxies for higher effective seniority.

This tax shares intuition with the systemic risk tax proposed in Acharya et al. (2010), in that both attempt to cause banks to internalize the negative externality that their actions impose on the rest of the financial system. The proposal of Acharya et al. is broader. It targets not just one risk factor but overall systemic risk and is therefore more comprehensive and able to capture future sources of vulnerability.

\section{Conclusion}

This paper analyzes the "dark side" of bank wholesale funding - insufficient monitoring and inefficient liquidations of banks by short-term wholesale financiers. The model suggests that wholesale funds can indeed be beneficially used in "traditional" banks that hold mostly opaque and non-tradable relationship loans. In contrast, these funds can create significant risks in "modern" banks that hold mostly arm's length assets with readily available, but noisy, public signals on their values. 


\section{A Proofs}

Lemma 1 Recall that:

$$
\Pi^{B}=p\left[D\left(X-R_{D}\right)+W(X-R)\right],
$$

and:

$$
R=\frac{W \rho+C\left(m^{W}\right)-m^{W}(1-p) s L(D+W)}{W p} .
$$

1a. Consider $d \Pi^{B} / d s$. Observe:

$$
\begin{aligned}
\frac{d \Pi^{B}}{d s} & =-W p \frac{d R}{d s} \\
& =-\left[\frac{d C\left(m^{W}\right)}{d s}-\frac{d m^{W}}{d s}(1-p) s L(D+W)-m^{W}(1-p) L(D+W)\right]
\end{aligned}
$$

Since:

$$
\frac{d C\left(m^{W}\right)}{d m^{W}}=(1-p) s L(D+W),
$$

we have:

$$
\frac{d C\left(m^{W}\right)}{d s}=\frac{d m^{W}}{d s}(1-p) s L(D+W)
$$

Substituting gives:

$$
\begin{aligned}
\frac{d \Pi^{B}}{d s} & =-\left[\frac{d m^{W}}{d s}(1-p) s L(D+W)-\frac{d m^{W}}{d s}(1-p) s L(D+W)-m^{W}(1-p) L(D+W)\right] \\
& =m^{W}(1-p) L(D+W)>0 .
\end{aligned}
$$

1b. Now consider $d \Pi^{B} / d W$. Observe: 


$$
\frac{d \Pi^{B}}{d W}=p(X-R)-W p \frac{d R}{d W}
$$

Solving $d R / d W$ and using similar substitution as above gives:

$$
\begin{aligned}
\frac{d \Pi^{B}}{d W} & =p(X-R)-W p\left[\frac{-m^{W}(1-p) s L \cdot W p-p \cdot\left[W \rho+C\left(m^{W}\right)-m^{W}(1-p) s L(D+W)\right]}{W^{2} p^{2}}\right] \\
& >0
\end{aligned}
$$

1c. Therefore $\Pi^{B}$ is increasing in $s$ and $W$ and is maximized for $s=1$ and $W=1-D$.

QED

Lemma 2 Recall:

$$
s^{W}=\frac{(1-\theta) p W R}{L(D+W)} .
$$

2.1a. We see immediately that:

$$
\frac{d s^{W}}{d \theta}=-\frac{p W R}{L(D+W)}<0
$$

2.1b. Consider $d s^{W} / d L$. Substitute $R$ :

$$
\begin{aligned}
\frac{d s^{W}}{d L} & =\frac{d}{d L}\left[(1-\theta) \frac{W \rho+C\left(m^{W}\right)-m^{W}(1-p) s L(D+W)}{L(D+W)}\right] \\
& =(1-\theta) \frac{\left[\frac{d C\left(m^{W}\right)}{d L}-\frac{d m^{W}}{d L}(1-p) s L(D+W)-m^{W}(1-p) s(D+W)\right] L(D+W)-(D+W}{L^{2}(D+W)^{2}}
\end{aligned}
$$

Recalling from the proof of Lemma 1 that:

$$
\frac{d C\left(m^{W}\right)}{d L}=\frac{d m^{W}}{d L}(1-p) s L(D+W)
$$

gives: 


$$
\begin{aligned}
\frac{d s^{W}}{d L} & =(1-\theta) \frac{-m^{W}(1-p) s L(D+W)-\left[W \rho+C\left(m^{W}\right)-m^{W}(1-p) s L(D+W)\right]}{L^{2}(D+W)} \\
& <0 .
\end{aligned}
$$

2.1c. Consider $d s^{W} / d D$. Observe that the numerator of $s^{W}$ decreases in $D$ since $d R / d D<0$ while the denominator increases in $D$. Therefore, $s^{W}$ decreases in $D$ : $d s^{W} / d D<0$.

2.1d. Under $D+W=1, \frac{d s^{W}}{d W}=-\frac{d s^{W}}{d D}>0$ by $2.1 \mathrm{c}$.

2.2-2.3. These were explained in text.

2.4. Consider the switch between $m^{W}$ and $m_{L i q}^{W}$ and between $R$ and $R_{L i q}^{W}$. We seek to show that these are continuous at $s^{W}$.

Observe that:

$$
\begin{aligned}
C^{\prime}\left(m_{s=s^{W}}^{W}\right) & =(1-p) s^{W} L(D+W) \\
& =p(1-p)(1-\theta) W R,
\end{aligned}
$$

and:

$$
\begin{aligned}
R_{s=s^{W}} & =\frac{W \rho+C\left(m_{s=s^{W}}^{W}\right)-m_{s=s^{W}}^{W}(1-p)(1-\theta) W p R_{s=s^{W}}}{W p} \\
& =\frac{W \rho+C\left(m_{s=s^{W}}^{W}\right)}{W p\left[1+m_{s=s^{W}}^{W}(1-p)(1-\theta)\right]} .
\end{aligned}
$$

Similarly,

$$
C^{\prime}\left(m_{L i q, s=s^{W}}^{W}\right)=p(1-p)(1-\theta) W R_{L i q, s^{W}},
$$

and:

$$
\begin{aligned}
R_{L i q, s=s^{W}} & =\frac{W \rho+C\left(m_{L i q, s=s^{W}}^{W}\right)-(1-p)(1-\theta) W p R_{L i q, s=s W}}{m_{L i q, s=s^{W}}^{W} W p+\left(1-m_{L i q, s=s^{W}}^{W}\right)[p+\theta(1-p)] W p} \\
& =\frac{W \rho+C\left(m_{L i q, s=s^{W}}^{W}\right)}{W p\left[1+m_{L i q, s=s^{W}}^{W}(1-p)(1-\theta)\right]} .
\end{aligned}
$$


It is evident that the two systems, the first of which defines $\left\{m_{s=s^{W}}^{W} ; R_{s=s^{W}}\right\}$ and the other $\left\{m_{L i q, s=s^{W}}^{W} ; R_{L i q, s=s^{W}}\right\}$, are identical.

QED

Lemma 3 Consider $\Delta \Pi^{B}$; recall we established that a bank always chooses $W=1-D$, so that:

$\Delta \Pi^{B}=p W\left[R_{s=s^{W}}-R_{L i q, s=1}\right]-\left(1-m_{C}\right) p(1-\theta)(1-p)\left[(1-W)\left(X-R_{D}\right)+W\left(X-R_{L i q, s=1}\right)\right]$.

Substitute expressions for $R_{s=s^{W}}$ and $R_{L i q, s=1}$ (using $m=m_{C}$ and $C\left(m_{C}\right)=0$ ):

$$
\begin{aligned}
R_{s=s^{W}} & =\frac{W \rho}{W p\left(1+m_{C}(1-p)(1-\theta)\right)} \\
R_{L i q, s=1} & =\frac{W \rho+C\left(m_{C}\right)-(1-p) L}{W p\left[m_{C}+\left(1-m_{C}\right)[p+\theta(1-p)]\right]}
\end{aligned}
$$

we obtain:

$$
\begin{aligned}
\Delta \Pi^{B}= & {\left[\frac{W \rho}{1+m_{C}(1-p)(1-\theta)}-\frac{W \rho-(1-p) L}{m_{C}+\left(1-m_{C}\right)[p+\theta(1-p)]}\right]-} \\
& -\left(1-m_{C}\right) p(1-\theta)(1-p)\left[X-(1-W) R_{D}-W \frac{W \rho-(1-p) L}{W p\left[m_{C}+\left(1-m_{C}\right)[p+\theta(1-p)]\right]}\right]
\end{aligned}
$$

We can now establish the signs of the first derivatives.

3a. Note immediately that $d \Delta \Pi^{B} / d L>0$.

3b. Note that the first term of $\Delta \Pi^{B}$ increases in $\theta: R_{s=s^{W}}$ increases in $\theta$ while $R_{L i q, s=1}$ decreases in $\theta$.

In the second term, the first multiplier (probability of incorrect liquidation) decreases in $\theta$, while the second multiplier (surplus lost in incorrect liquidations) increases because $R_{L i q, s=1}$ declines. Yet the first effect dominates, so that the second term increases in $\theta$ :

$$
\begin{aligned}
& \frac{d}{d \theta}\left[\left(1-m_{C}\right) p(1-\theta)(1-p)\left[W \frac{W \rho-(1-p) L}{W p\left[m_{C}+\left(1-m_{C}\right)[p+\theta(1-p)]\right]}\right]\right] \\
= & \frac{[W \rho-(1-p) L]\left(1-m_{C}\right)(1-p)}{\left[m_{C}+\left(1-m_{C}\right)[p+\theta(1-p)]\right]^{2}}>0 .
\end{aligned}
$$

Therefore both terms increase in $\theta$ and $d \Delta \Pi / d \theta>0$. 
3c-d. We examine $d \Delta \Pi^{B} / d W ; d \Delta \Pi^{B} / d D$ is inverse since a bank chooses $W=1-D$.

The first term of $\Delta \Pi^{B}$ decreases in $W$ :

$$
\begin{aligned}
& \frac{d}{d W}\left[\frac{W \rho}{1+m_{C}(1-p)(1-\theta)}-\frac{W \rho-(1-p) L}{m_{C}+\left(1-m_{C}\right)[p+\theta(1-p)]}\right] \\
= & -\rho \frac{(1-p)(1-\theta)}{\left(m_{C}+\left(1-m_{C}\right)[p+\theta(1-p)]\right)\left(1+m_{C}(1-p)(1-\theta)\right)}<0 .
\end{aligned}
$$

In the second term, two factors affect the bank's loss in incorrect liquidations. First, $R_{L i q}$ decreases in $W$ and therefore increases the bank's surplus. Second, the shift from depository funding at cost $R_{D}$ to wholesale funding at cost $R_{L i q}$ increases the bank's surplus for $R_{D}>R_{L i q}$ or reduces it for $R_{D}<R_{L i q}$.

However, overall, the effects stemming from the first term dominate, and $d \Delta \Pi / d W<0$. Indeed, consider:

$$
\begin{aligned}
\frac{d \Delta \Pi^{B}}{d W}= & \frac{\rho}{1+m_{C}(1-p)(1-\theta)}-\frac{\rho}{m_{C}+\left(1-m_{C}\right)[p+\theta(1-p)]} \\
& -\left(1-m_{C}\right)(1-\theta)(1-p) \frac{p\left[m_{C}+\left(1-m_{C}\right)[p+\theta(1-p)]\right] R_{D}-\rho}{\left[m_{C}+\left(1-m_{C}\right)[p+\theta(1-p)]\right]} \\
= & -\frac{(1-p)(1-\theta)\left(1+\left(1-m_{C}\right)\left[p\left[m_{C}+\left(1-m_{C}\right)[p+\theta(1-p)]\right] R_{D}-\rho\right]\right)}{\left[m_{C}+\left(1-m_{C}\right)[p+\theta(1-p)]\right]\left[m_{C}+\left(1-m_{C}\right)[p+\theta(1-p)]\right]} .
\end{aligned}
$$

Now arrange the fraction and consider solely the numerator (the denominator is positive):

$$
\begin{aligned}
& \rho\left[m_{C}+\left(1-m_{C}\right)[p+\theta(1-p)]\right]-\rho\left[1+m_{C}(1-p)(1-\theta)\right] \\
& +\rho\left(1-m_{C}\right)(1-\theta)(1-p)\left[1+m_{C}(1-p)(1-\theta)\right]-\xi R_{D}
\end{aligned}
$$

where $\xi$ is a positive coefficient. Arranging the terms yields:

$$
\begin{aligned}
& \rho(1-p)(1-\theta)\left(1-m_{C}\right)\left(\left[1+m_{C}(1-p)(1-\theta)\right]-1\right)-\xi R_{D} \\
< & \rho(1-p)(1-\theta)\left(1-m_{C}^{2}-1\right)-\xi R_{D} \\
= & -m_{C}^{2} \rho(1-p)(1-\theta)-\xi R_{D}<0 .
\end{aligned}
$$

Therefore $d \Delta \Pi^{B} / d W<0$ and $d \Delta \Pi^{B} / d D>0$. 


\section{References}

Acharya V.V., Gale D., and Yorulmazer T., 2008, "Rollover Risk and Market Freezes," Working Paper, NYU Stern.

Acharya V.V., Pedersen L.H., Philippon T., and Richardson M., 2010, "A Tax on Systemic Risk," Working Paper, NY Stern.

Billett M.T., and Garfinkel J.A., 2004, "Financial Flexibility and the Cost of External Finance for U.S. Banks," Journal of Money, Credit and Banking, 36(5):827-52.

Billett M.T., Garfinkel J.A., and O’Neal E.S., 1998, "The Cost of Market versus Regulatory Discipline in Banking," Journal of Financial Economics, 48(3):333-358.

Calomiris C., 1999, "Building an Incentive-Compatible Safety Net," Journal of Banking \& Finance, 23(10):1499-1519.

Calomiris C., and Kahn C., 1991, "The Role of Demandable Debt in Structuring Optimal Banking Arrangements," American Economic Review, 81(3):497-513.

Diamond D.W., and Dybvig P., 1983, "Bank Runs, Deposit Insurance, and Liquidity," Journal of Political Economy, 91(3): 401-19.

Feldman R., and Schmidt J., 2001, "Increased Use of Uninsured Deposits: Implications for Market Discipline," Federal Reserve Bank of Minneapolis-Fed Gazette March: 18-9.

Flannery M., 1982, "Retail Bank Deposits as Quasi-Fixed Factors of Production," American Economic Review, 72(3):527-36.

Goodfriend M., and King R.G., 1998, "Financial Deregulation, Monetary Policy, and Central Banking," Fed. Reserve Bank Richmond Econ. Rev. May/June, 3-22.

Huang, R., and Ratnovski, L., 2009, "Why Are Canadian Banks More Resilient?" IMF Working Paper 09/152.

Kim M., Kliger D., and Vale B., 2003, "Estimating Switching Costs: The Case of Banking," Journal of Financial Intermediation, 12(1):25-56.

Marino J.A., and Bennett R.L., 1999, "The Consequences of National Depositor Preference," FDIC Banking Review, October:19-38.

Perotti E., and Suarez J., 2009, "Liquidity Insurance for Systemic Crises," CEPR Policy Insight No 31.

Rochet J.-C., and Vives X., 2004, "Coordination Failures and the Lender of Last Resort: Was Bagehot Right After All?" Journal of the European Economic Association, 2(6):1116-47. 
Sharpe S.A., 1990, "Asymmetric Information, Bank Lending, and Implicit Contracts: A Stylized Model of Customer Relationships," Journal of Finance, 45(4):1069-87.

Sharpe S.A., 1997, "The Effect of Consumer Switching Costs on Prices: A Theory and Its Application to the Bank Deposit Market," Review of Industrial Organization, 12(1):79-94.

Shin H.S., 2008, "Reflections on Modern Bank Runs: A Case Study of Northern Rock," Working Paper, Princeton University.

Song F., Thakor A.V., 2007, "Relationship Banking, Fragility, and the Asset-Liability Matching Problem," Review of Financial Studies, 20(6): 2129-77.

von Thadden E.-L., 1995, "Long-Term Contracts, Short-Term Investment and Monitoring," Review of Economic Studies, 62(4):557-75.

von Thadden E.-L., 2004, "Asymmetric Information, Bank Lending, and Implicit Contracts: The Winner's Curse," Finance Research Letters 1(1):11-23.

Yorulmazer T., 2008, "Liquidity, Bank Runs and Bailouts: Spillover Effects During the Northern Rock Episode," Working Paper, Federal Reserve Bank of NY. 


\section{Figure 1.}

The wholesale financier's monitoring and liquidation decisions.

The left panel illustrates the benchmark case without a noisy public signal: the wholesale financier's intensity of monitoring $m$ increases monotonically in his creditor seniority $s$. The right panel depicts the case with a noisy signal. There, when seniority exceeds the threshold value $s=s^{W}$, the wholesale financier starts to reduce his intensity of monitoring in response to higher seniority.

\section{Without a noisy signal}

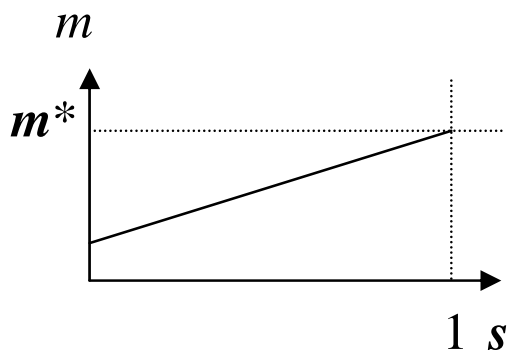

\section{With a noisy signal}

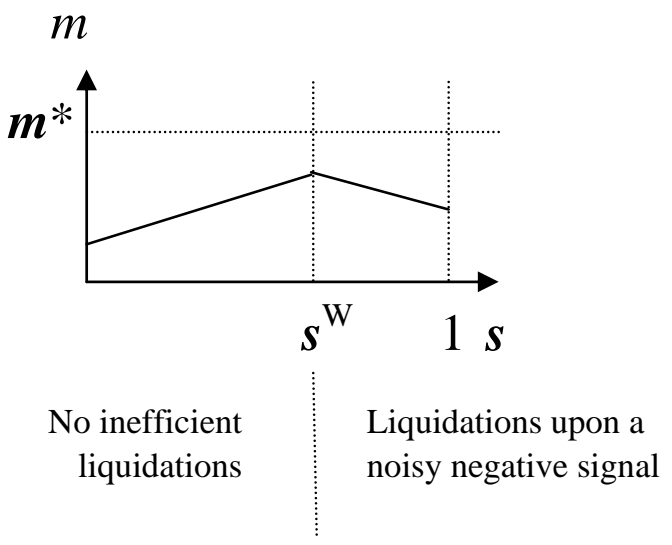




\section{Figure 2.}

\section{The bank's surplus depending on the wholesale financier's seniority.}

The figures depict the bank's surplus $\Pi^{B}$ as a function of the wholesale financier's creditor seniority s. The left panel shows the bank's surplus in the benchmark case without a noisy signal. The right panel shows the case with the noisy signal. There, the continuous lines and the shaded area between them represent shapes complying with the $m=m_{C}$ assumption (all linear), while the broken lines represent examples of shapes ruled out by that assumption. The point $s^{W}$ is the threshold beyond which the wholesale financier liquidates a bank based on a negative public signal.

\section{Without a noisy signal}

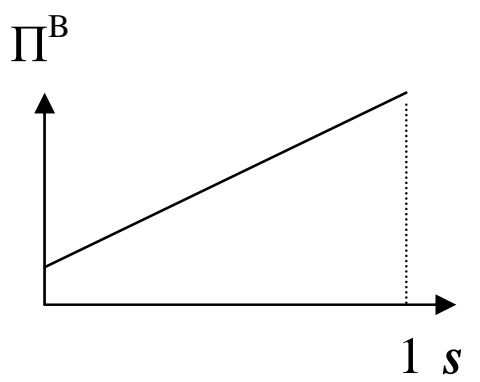

\section{With a noisy signal}

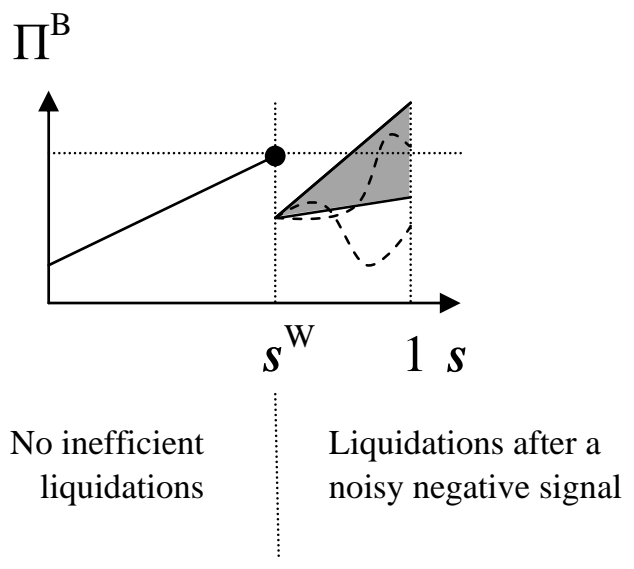




\section{Figure 3.}

\section{The bright and dark sides of bank wholesale funding.}

Line 1 represents pairs of signal precision $\theta$ and liquidation value $\mathrm{L}$ that satisfy $\Delta \Pi^{B}=0$. All points below that line satisfy $\Delta \Pi^{B} \geq 0$ so that the bank has the incentive to assign socially optimal seniority $s^{W}$ to the wholesale financier, corresponding to the "bright side" of wholesale funding. All points above that line satisfy $\Delta \Pi^{B}<0$ so that the bank has the incentive to assign too high seniority $s=1$ to wholesale funds, corresponding to the "dark side."

The other lines represent additional parameter restrictions used in the model. Line 2 is $\theta>\theta^{W}{ }_{s=1}$ (existence of inefficient liquidations; indistinguishable from line 1 in the middle graph). Line 3 is $\theta<\theta^{*}$ (early liquidations based on noisy signals are not socially optimal). Line 4 is a tractability restriction $p W>L$, corresponding to non-negligible wholesale funding.

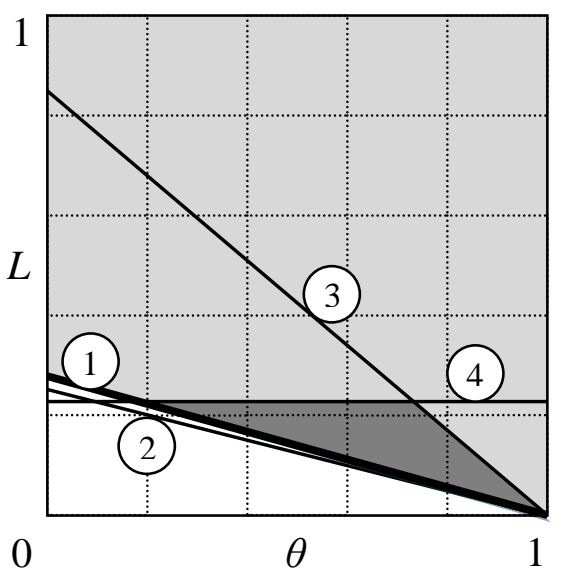

Low use of wholesale funding, $\mathrm{W}=0.25$

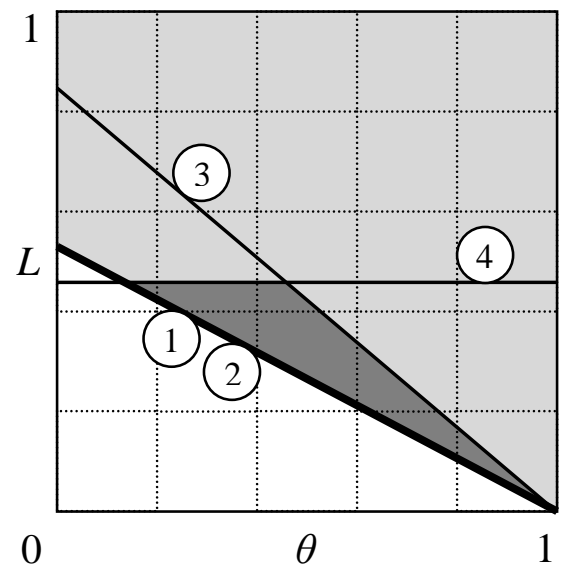

Intermediate use of wholesale funding, $\mathrm{W}=0.50$

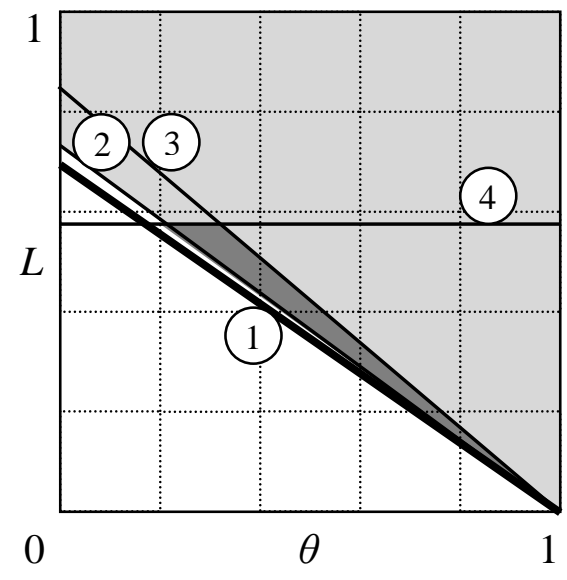

High use of wholesale funding, $\mathrm{W}=0.75$ 